\title{
Método para Determinação de VSP por Meio de Pesquisa Colaborativa
}

\author{
FORCETTO, André Luiz Silva ${ }^{1}$ \\ SALVO Jr., Orlando de ${ }^{2}$ \\ ${ }^{1}$ CETESB - Companhia Ambiental do Estado de São Paulo \\ ${ }^{2}$ Escola Politécnica da Universidade de São Paulo \\ E-mails: ${ }^{1}$ aforcetto@sp.gov.br, ${ }^{2}$ osalvo.junior@usp.br
}

\section{RESUMO}

Os veículos automotores têm forte influência nas emissões de poluentes e na concentração de CO2 na atmosfera. Devido às divergências entre as medições de poluentes e CO2 em laboratório e em condições reais de condução, foi desenvolvido o teste de Emissões em Condução Real (RDE - Real Driving Emissions), onde o veículo é avaliado nas ruas sob condições reais de tráfego, embora sabe-se que o comportamento do condutor, entre outros fatores, tem influência nos resultados. O método de cálculo da Potência Específica do Veículo (VSP - Vehicle Specific Power), através de dados de sistemas globais de navegação por satélite (GNSS - Global Navigation Sattelite System, por exemplo: GPS) como velocidade e aceleração do veículo e inclinação da pista, é capaz de medir o quanto o condutor é agressivo na direção e pode avaliar sua influência nos resultados de um teste RDE. O VSP também permite estimar o consumo de combustível e as emissões de $\mathrm{CO}_{2}$ através de softwares de modelagem de emissões. $O$ objetivo desse artigo é trazer uma proposta para um método para determinar valores típicos de VSP através de Pesquisa Colaborativa, onde voluntários registram suas viagens por meio do GPS de seus próprios aparelhos celulares. A baixa acurácia é compensada pelo alargamento da base amostral, porém deve-se haver o cuidado de se filtrar ruídos e imprecisões de medição. Esse método permite cobrir mais e diversas condições de tráfego, clima e comportamento ao dirigir, bem como reduzir o tempo necessário para se obter um montante significativo de dados, pois as medições são feitas por várias pessoas simultaneamente.

\section{INTRODUÇÃO}

O crescimento contínuo da população nas regiões urbanas associado ao aumento no consumo de combustíveis fósseis tem levado a um quadro de degradação da qualidade do ar e consequentemente afetando a saúde da população, e este quadro se torna mais agudo em países com baixa renda per capta [1].

A queima de combustíveis fósseis, em função da demanda por energia e pelo setor de transportes, principalmente nos centros urbanos, também causa emissão de Gases de Efeito Estufa (GEE) para a atmosfera, provocando mudanças climáticas [2], não sendo ainda 
observada a tendência de redução destes índices. O setor de transporte tem ampla responsabilidade nestas emissões, com participação de $15 \%$ da emissão global de carbono pelos veículos de passageiros, segundo a Organização para a Cooperação e Desenvolvimento Econômico (OECD) [3].

O resultado das emissões está intimamente ligado ao modo de condução, tecnologia embarcada, condição topográfica das vias, entre outros [4]. Além desses fatores, as emissões são afetadas pelo tamanho da frota. Como exemplo, o grande crescimento da frota chinesa nas últimas décadas trouxe a preocupação com a segurança energética, problemas com a poluição e congestionamentos, em um mercado que continua em expansão. Desde a década passada, a regulamentação tem estreitado os limites de consumo de combustível e emissões de forma a reduzir os impactos decorrentes ao crescimento da frota [5].

A regulamentação tem potencializado a mudança tecnológica em automóveis e combustíveis, e o resultado das emissões devem ser consideradas em condições reais de rodagem, que melhor reflete as emissões na atmosfera. Considerando os limites impostos para veículos novos, uma verificação periódica permite aferir o nível de emissões ao longo da vida do veículo. A inspeção veicular pode monitorar as condições de uso dos veículos ao longo do tempo, mas nem todas as localidades realizam este procedimento, e os métodos de cada região variam [6].

Em função de divergências entre os resultados obtidos em teste em dinamômetro com base em ciclo padrão e das emissões medidas em campo, como em experimento em túneis e por sensoriamento remoto, tem-se como resultado a subestimação das emissões da frota. Assim, foi desenvolvido no início dos anos 1990 o conceito de emissão em condições reais de condução (RDE - Real Driving Emissions), no entanto, o padrão de condução de cada motorista durante o percurso tem grande influência nas emissões de GEE e poluentes.

O método de cálculo da Potência Específica do Veículo (VSP - Vehicle Specific Power) permite estimar valores de consumo e emissões e também é útil para se avaliar o comportamento do motorista ao conduzir o veículo. Portanto, o objetivo deste artigo é propor um método para determinação de valores típicos de VSP, baseado em receptor de posicionamento "built-in" de celular e aplicativos de rastreamento e que mantenha a confiabilidade dos resultados.

\section{REVISÃO TEÓRICA}

Os veículos leves têm padrões de uso e modos de condução relacionados às características dos trajetos e do tipo de uso demandados a cada tipo veículo; o padrão de condução de cada motorista tem forte influência nas emissões de GEE e poluentes.

Há simuladores que permitem estimar as emissões GEE de veículos particulares, como o modelo da Agencia Ambiental dos Estados Unidos (EPA), o MOVES. Este é o preferido por alguns pesquisadores por combinar o método VSP com padrão de velocidade, o tempo de operação do veículo e permite relacionar base de dados com múltiplas escalas [3]. Os valores básicos utilizados para os fatores de emissões de veículos, aplicados nos softwares de modelagem para criação de modelos para estimativa de emissões de GEE e poluentes, têm como origem os ensaios padronizados, realizados em laboratório, que visam reproduzir 
as condições de rodagem da região [1]. No entanto, estes fatores são questionados por apresentar divergência com os parâmetros de medições em condição reais de uso, devido que o teste é baseado em ciclos que nem sempre representam as condições reais do modo de condução usual [7].

Em função dos ciclos de teste em dinamômetro divergir das condições reais de rodagem dos veículos e suas respectivas emissões, há uma subestimação das emissões da frota, por isso foi estabelecido no início dos anos de 1990 o conceito de emissão em condições reais de condução (RDE - Real Driving Emissions). Esta medição subestimada tem como consequência a degradação da qualidade do ar, mesmo diante de padrões mais restritivos de emissões, estabelecidos pela regulamentação ambiental [1]. Alguns estudos na China e Europa apontam também diferença a maior entre o consumo com base em teste RDE e o ciclo de teste oficial. Estas divergências entre os valores "oficiais" e "reais" mais que dobraram entre 2000 e 2011, e um dos principais indutores deste aumento tem sido a utilização de tecnologias embarcadas, que promovem melhores resultados no teste em laboratório, mas não se confirmam em testes RDE. Além disto, outros fatores importantes são o maior uso do ar condicionado e aumento nos congestionamentos, o que reduz a velocidade média dos veículos [5].

Um dos métodos para a medição das emissões em vias de circulação é por sensoriamento remoto ótico (RSD - Remote Sensing Device). Apesar de apresentar melhor precisão e representatividade das emissões, tem algumas limitações como em condições de baixa vazão (marcha lenta ou desaceleração) e baixa temperatura. Ainda assim, este método tem permitido o monitoramento das emissões da frota, sendo comprovado a redução das emissões ao longo do tempo, assim como a dependência das emissões em relação ao VSP. A medição por meio de sensoriamento nas vias apresenta discrepância em relação à realizada em laboratório, que pode ser explicada em parte pelo padrão de condução utilizado nos ciclos de teste, que não representa plenamente o comportamento do motorista nas ruas. Esta variação entre os métodos, oficial e real, de medições demanda o desenvolvimento de cálculo de inventário por meio de padrões que melhor representem a realidade. Estudos anteriores apontaram a divergência também entre modelos teóricos, como o COPERT, por exemplo, e a medição real [6].

O levantamento em condições reais de condução pode ser feito por meio de sistema de posicionamento global por satélite (GNSS - Global Navigation Sattelite System, por exemplo: o sistema americano GPS; daqui em diante GNSS e GPS serão tratados como sinônimos, para simplificação) ou pela unidade de controle eletrônica do motor (ECU), o que permite adquirir parâmetro de várias horas de rodagem. As informações requeridas são a velocidade e a altitude do veículo, de forma a identificar as variações de rodagem, diferente do que ocorre em dinamômetro. Estes dados são levantados com custo relativamente baixo. Caso haja a medição das emissões por meio de analisador portátil (PEMS - Portable Emissions Measurement System), o custo passa a ser mais relevante, de modo a limitar a amostragem de aquisição de emissões. Os dados aquisitados são processados de forma a representar, pelo valor do VSP, a agressividade do modo de condução, diferente do padrão realizado em laboratório [1]. 
O conceito de VSP foi desenvolvido inicialmente por Jiménez, no Instituto de Tecnologia de Massachusetts (MIT - Massachusetts Institute of Technology) e consiste da soma da carga referente à aceleração do veículo, da sua resistência à rolagem e da potência para vencer aclives, em relação à massa do mesmo [8].

O método VSP recebe dados de rodagem para que modelos matemáticos possam calcular os valores de emissões de $\mathrm{CO}, \mathrm{CO}_{2}$ e $\mathrm{HC}$. Os parâmetros necessários são a velocidade e aceleração do veículo e a inclinação da via. Os valores de aceleração e velocidade podem ser adquiridos pela ECU do veículo, mas a inclinação depende de dados de posicionamento por satélite. $O$ valor da inclinação da via tem grande influência no consumo de combustível, e a imprecisão na medição da altitude tem relação direta no resultado do consumo [9]. Além de alimentar o modelo VSP, os dados levantados em rodagem podem contribuir para refinar a base de dados de programas para simulação de consumo e emissões com base em ciclo de rodagem $\mathrm{RDE}[10]$.

O PEMS com o GPS é instalado no veículo e são realizadas medições a cada segundo das emissões e do posicionamento. Os dados de posicionamento por satélite são posteriormente tratados por meio de vinculação ao mapa para calcular a inclinação de pista e os valores de velocidade e aceleração do veículo. Para vincular os parâmetros de posicionamento, os dados armazenados pelo GPS devem ser importados em um programa GIS (Geographic Information System) para ajustes de latitude e longitude do GPS, de forma a corrigir os valores de inclinação de pista [11]. As medições verticais, para o cálculo da inclinação de pista, podem apresentar erros significativos no caso de mudanças das observáveis dos satélites, e também em locais com baixo sinal de GPS em função de obstruções por túneis, árvores ou edificações [12].

A combinação dos dados coletados em rodagem com as taxas de consumo e emissões do método VSP permite estimar os valores de consumo e emissões, inclusive classificando por tipos de tecnologia de alimentação de combustível. Estimativas com base na taxa VSP não têm necessidade da medição física do consumo [13], [14].

\section{EQUIPAMENTOS E SOFTWARES PARA MEDIÇÃO DO VSP}

O equipamento mínimo requerido para se realizar o levantamento de VSP consiste simplesmente de um veículo, que irá transitar nas vias que serão avaliadas, e de um receptor GPS para o registro dos dados de latitude, longitude, altitude e tempo decorrido. No entanto, as opções sobre a escolha do hardware a se utilizar são derivadas das limitações dos próprios equipamentos e do método adotado para o levantamento de dados.

Uma pesquisa executada com um único veículo requererá um período de tempo elevado, pois este deverá rodar por vários dias e em diversos horários para se obter uma amostragem significativa. Ao se utilizar apenas um condutor, também haverá um viés devido à influência direta do comportamento deste nos valores de aceleração e desaceleração médios, portanto, é fundamental haver revezamento de condutores. O cenário ideal para desenvolver uma pesquisa como esta, que envolve variáveis de comportamento do indivíduo e de condições de tráfego, é que seja realizada com diversos veículos e motoristas, sendo possível também reduzir o tempo requerido para levantamento dos dados. 
Em relação ao receptor GPS, há vários modelos a disposição, desde equipamentos de alta precisão, com taxas de amostragem acima de $10 \mathrm{~Hz}$, bem como aparelhos comerciais básicos, com amostragem de $1 \mathrm{~Hz}$, e até mesmo aplicativos de celular, com precisão similar aos receptores básicos comerciais. A primeira escolha tende a ser o aparelho de alta precisão, mas o grande fator limitante é seu custo, que pode chegar a alguns milhares de dólares, o que dificulta disponibilizar várias unidades para realizar o levantamento de dados. Os equipamentos GPS comerciais para veículos têm caído em desuso pela facilidade atual de o usuário comum utilizar aplicativos de celular, que vão além das informações do mapa da região e opções de rota, pois possibilitam a interação entre usuários e permitem a escolha do caminho mais rápido e que evite congestionamentos e outros problemas de tráfego. A exatidão das coordenadas de aparelhos comerciais e de aplicativos de celular é menor do que a de receptores de alta precisão, porém não afetam o resultado final para o usuário comum que deseja tão somente chegar a determinado local do modo mais ágil.

O levantamento de coordenadas por GPS é um procedimento amplamente utilizado em pesquisas acadêmicas, porém é importante destacar que possui limitações inerentes à sua própria concepção, afetando inclusive os resultados obtidos em receptores de alta precisão. Em primeiro lugar, pode haver erro nas coordenadas, devido que a recepção dos sinais dos satélites está sujeita a sombras e reflexões de grandes obstáculos, como montanhas e edifícios, e interferências atmosféricas, tanto na ionosfera como na troposfera, devido a fenômenos de atenuação, refração, cintilação, reflexão, bloqueio, espalhamento e difração [15]. Em segundo lugar, o GPS pode apresentar pequenas variações ou saltos ao executar o cálculo das coordenadas, ao se alternar os satélites que estão a fornecer os dados de posição [16]. Devido a estes fatores, a incerteza de posição de receptores GPS é de cerca de 3 metros na horizontal, mesmo para aparelhos de precisão. Estes contam com outros recursos para incremento da exatidão, como a tecnologia RTK, que liga o instrumento a uma base fixa e possibilita precisão dentro de $0,1 \mathrm{~m}$, mas têm alcance limitado. Este ruído é representativo no cálculo do VSP e deve ser minimizado através de filtros matemáticos.

Os receptores comerciais, tanto de alta precisão como os de uso geral, já vêm com os softwares necessários. Já no caso de se realizar a coleta de dados por meio de celular, há várias opções de aplicativos, tanto gratuitos como pagos, que podem ser baixados em lojas virtuais de softwares, como a Google Play Store para o sistema Android, e que executam o registro das coordenadas e demais informações que caracterizam um trajeto. Neste artigo foram testados os aplicativos "Velocímetro GPS Pro" (pago) e "Geo Tracker" (gratuito), instalados em aparelhos Motorola E 2a. Geração e Samsug J5 Metal.

\section{PROCEDIMENTO PARA COLETA DE DADOS}

O método aqui proposto para o levantamento do VSP é a coleta os dados por meio de Pesquisa Colaborativa, onde diversos voluntários, arregimentados por meio de networking, divulgação em sites corporativos, etc., irão realizar o registro de seus trajetos por meio de aplicativo de celular. Ao realizar um percurso qualquer, o voluntário ativa a localização por GPS, abre o aplicativo de rastreamento e inicia a coleta de dados momentos antes de iniciar o deslocamento, finalizando a coleta quando concluir o trajeto. Os dados do software, em formato *.gpx, são posteriormente enviados para a equipe de pesquisa, junto com de outras 
informações relevantes, como o modelo do veículo, condutor (idade, escolaridade e gênero), clima e percepção de intensidade de tráfego.

Para este trabalho foram realizados registros de vários percursos, com veículos e condutores diferentes. Os testes práticos mostraram que o melhor ajuste para os aplicativos foi com o registro de coordenadas a cada 1 segundo e o celular com o GPS em modo "normal". O aparelho pode também trabalhar no modo "alta precisão", que apresenta algum ganho na exatidão nas coordenadas, mas ainda assim continua com taxa de amostragem de $1 \mathrm{~Hz}$, portanto com menor precisão do que um receptor de $10 \mathrm{~Hz}$.

Como exemplo da metodologia apresentada, foi analisado um trajeto realizado entre a USP Cidade Universitária e a FATEC Santo André. A Figura 1 mostra a tela do aplicativo, com este percurso em destaque.

\section{Figura 1 - Trajeto USP Cidade Universitária - FATEC Santo André}

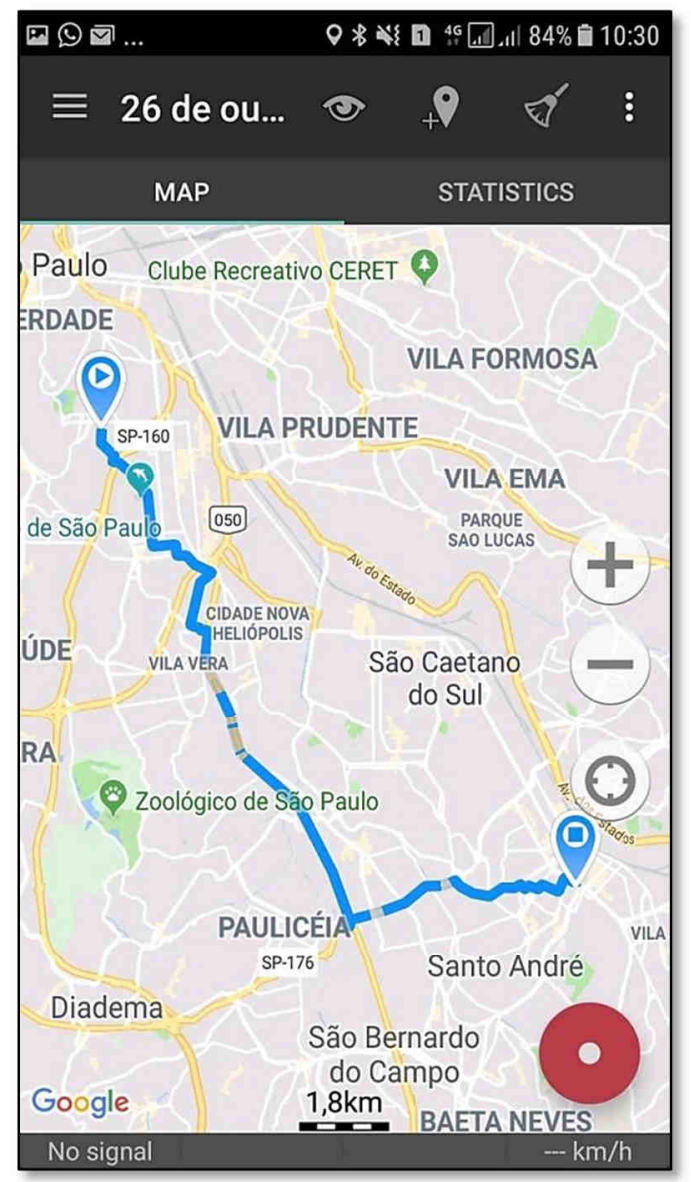

Os gráficos resultantes sem qualquer filtro (dados brutos) estão representados na Figura 2 para a velocidade do veículo e o histograma dos valores VSP na Figura 3. 
Figura 2 - Velocidade ao longo do trajeto de teste - dados brutos

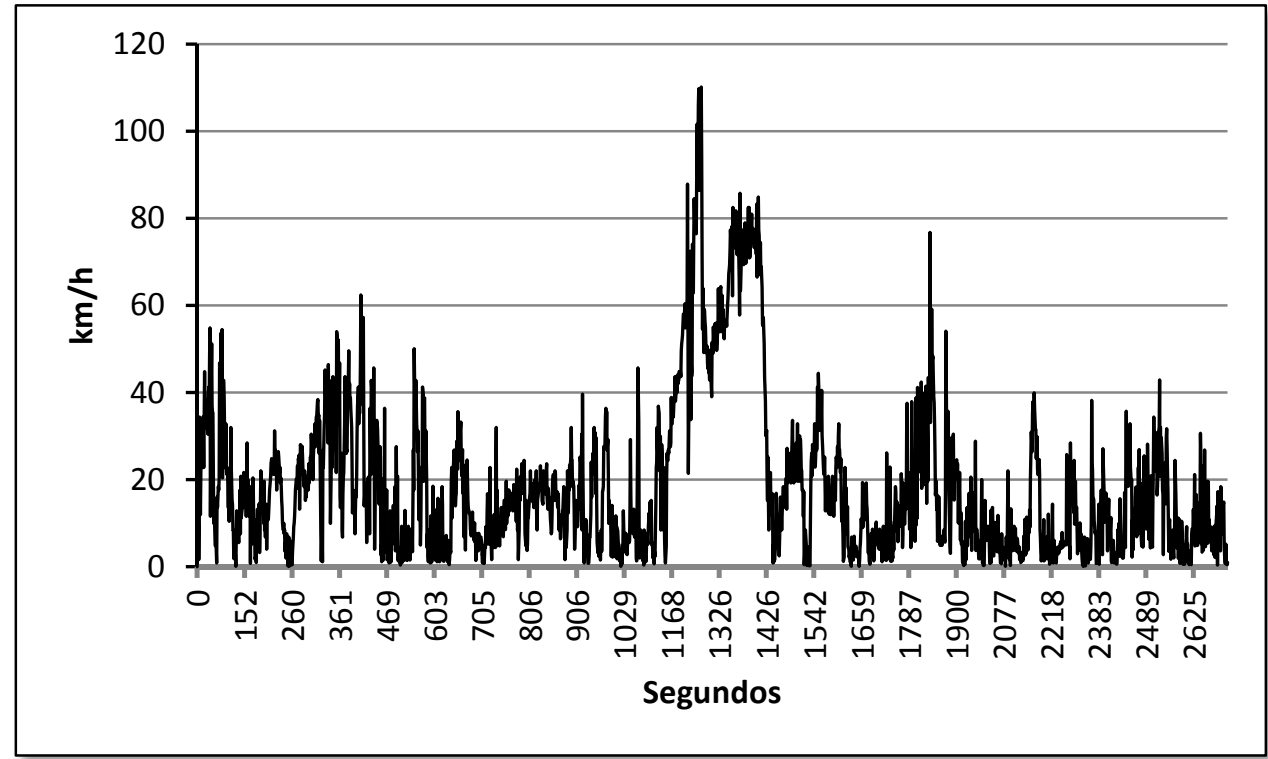

Figura 3 - Histograma do VSP do trajeto de teste - dados brutos

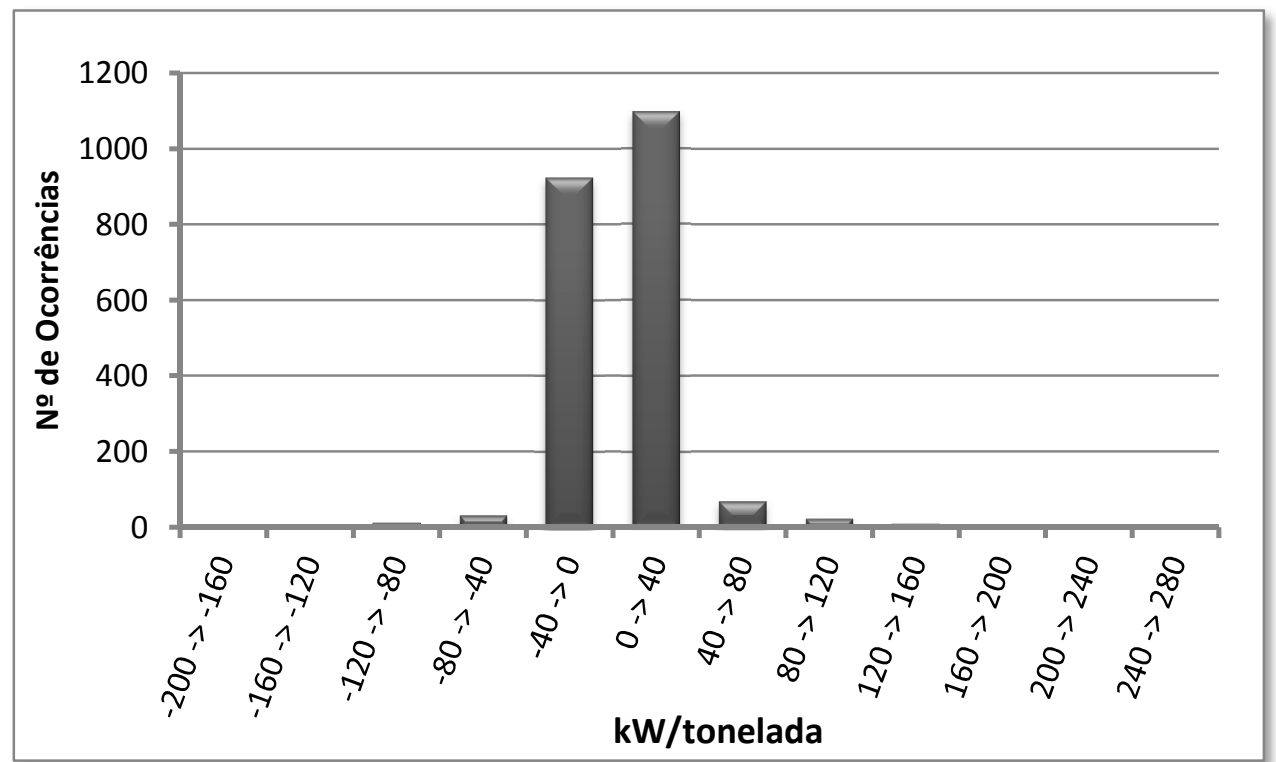

\section{TRATAMENTO DOS DADOS}

As informações coletadas por meio de coordenadas GPS devem ser filtradas para se eliminar os ruídos que o próprio sistema introduz nas medições. Os seguintes métodos foram testados:

- Reagrupamento de pacotes de tempo: os pontos do trajeto são reagrupados em intervalos mínimos (igual ou maior a) de tempo. A aplicação deste filtro resultou em uma atenuação intensa, podendo causar uma distorção indesejada nos valores de VSP. 
- Reagrupamento de pacotes de distância: os pontos são reagrupados em intervalos mínimos de distância. Foi constatado ruído significativo nas distâncias menores que $3 \mathrm{~m}$, assim este filtro se mostrou útil para a correção dos dados de coordenadas horizontais.

- Cálculo de média móvel de velocidade e altitude: os valores são recalculados ponto a ponto pela média de valores do ponto em análise e valores anteriores e posteriores. Este filtro se mostrou relevante para a atenuação do ruído remanescente das coordenadas horizontais e das variações das coordenadas verticais.

Os reagrupamentos de tempo e/ou distância em pacotes de tamanho mínimo amenizam a característica da medição por GPS de variações indesejadas no cálculo das coordenadas, pois o receptor usualmente aponta pequenos deslocamentos horizontais e verticais, devido às interferências, mesmo que o veículo esteja parado [15]. A atenuação de variações abruptas da velocidade calculada através de média móvel é uma ferramenta matemática simples que possibilita a redução de ruído, ao mesmo tempo em que preserva a resposta à variação dos dados medidos [17], [18].

Os melhores resultados, após testes de várias ferramentas e configurações, foram alcançados com os seguintes critérios:

- Manter o agrupamento de tempo original ( $\mathbf{T} \geq 1 \mathrm{~s}$ ), pois o reagrupamento por tempo mostrou atenuação excessiva;

- Reagrupamento dos segmentos de distância $\mathbf{S}$ percorrida em pacotes iguais ou maiores que $5 \mathrm{~m}$;

- Recálculo da velocidade calculada $(\mathbf{V}=\Delta \mathbf{S} / \Delta \mathbf{T})$ por meio de média móvel com 5 pontos;

- Recálculo da altitude por meio de média móvel com 5 pontos.

Foram também testados critérios de maior atenuação, como reagrupamento de distância mínima de 10 metros e médias móveis de velocidade e altitude com 7 e 10 pontos, com resultados finais de VSP muito próximos aos obtidos com a configuração acima, portanto optou-se por se manter a filtragem dentro do mínimo necessário, para evitar uma distorção indesejável dos resultados finais de VSP.

Por fim, é importante destacar que o conjunto de dados deve ser submetido à análise estatística para determinação de grau de variabilidade e confiabilidade e se chegar ao resultado final da VSP típica de determinado trecho ou região.

A Figura 4 mostra o gráfico de velocidade com filtragem por média móvel, a Figura 5 traz em detalhe os primeiros 200 segundos, comparando os dados brutos da velocidade com os valores filtrados por média móvel de 5 componentes; por fim, a Figura 6 mostra os valores de VSP do mesmo percurso USP-FATEC mostrado na Figura 3, com os filtros aplicados. 
Figura 4 - Velocidade ao longo do trajeto de teste - dados filtrados

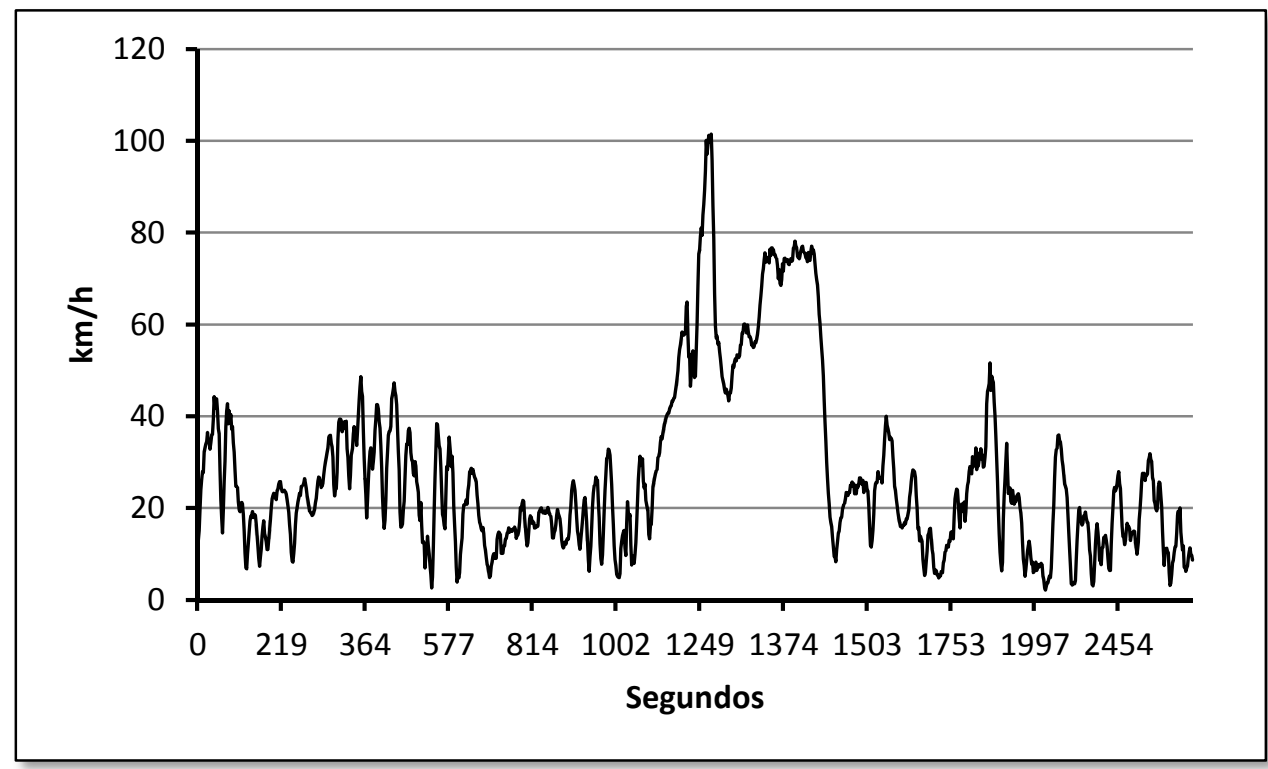

Figura 5 - Velocidade ao longo do trajeto - dados brutos $x$ dados filtrados

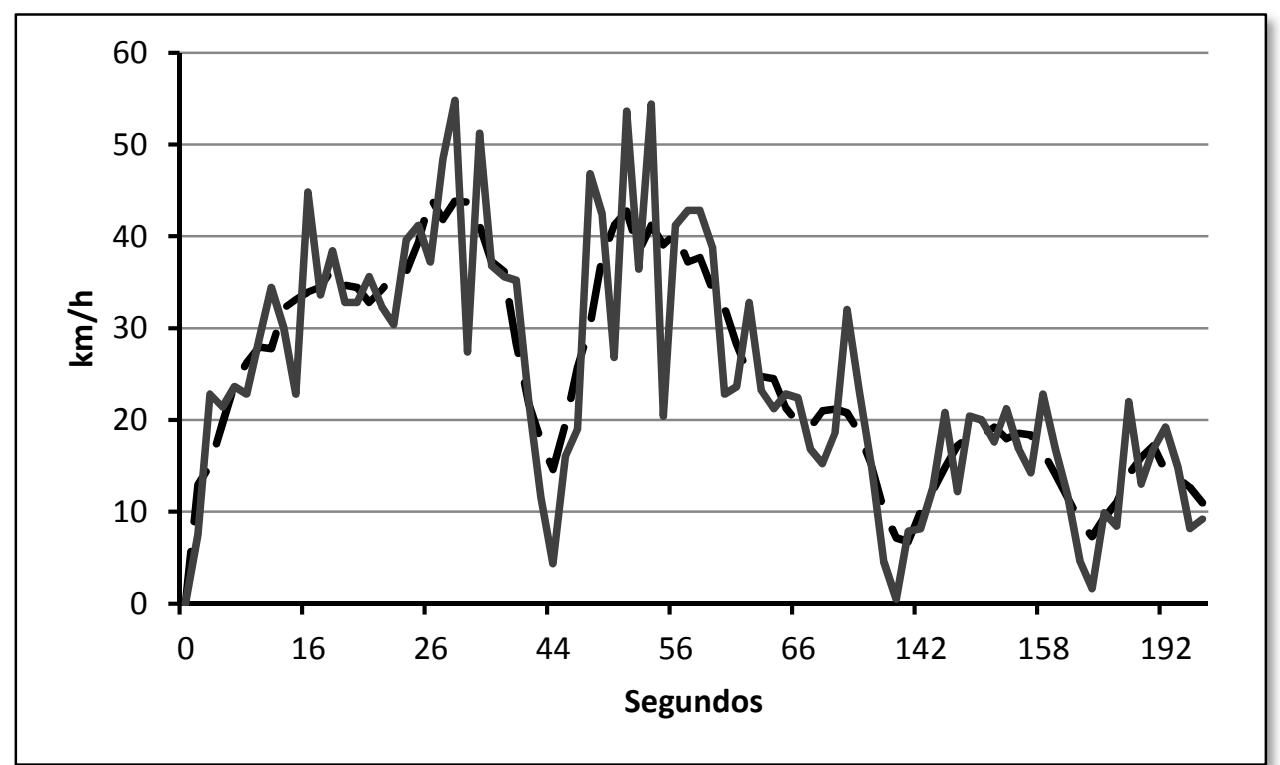


Figura 6 - Histograma do VSP do trajeto de teste-dados filtrados

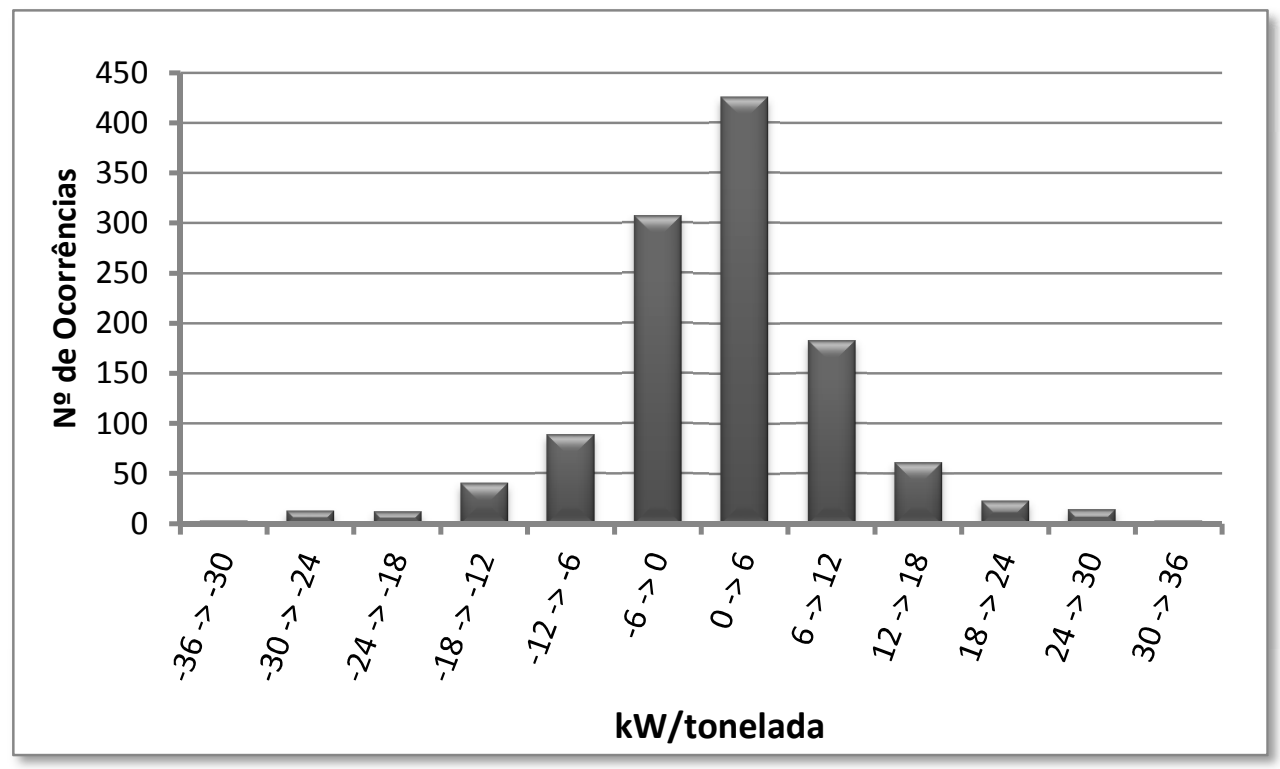

A título de comparação, a Figura 7 traz o histograma do ciclo de ensaio de laboratório de emissões FTP-75, que é o utilizado para homologação de veículos no Brasil [19]. Percebe-se que os valores tem uma variação mais estreita, concentrados na faixa de -18 a +24 $\mathrm{kW} /$ tonelada. Tendo em vista que no ensaio laboratorial o veículo não é submetido a aclives e declives, esta diferença do VSP real em relação ao FTP-75 é coerente.

Figura 7 - Histograma do VSP do ciclo FTP-75

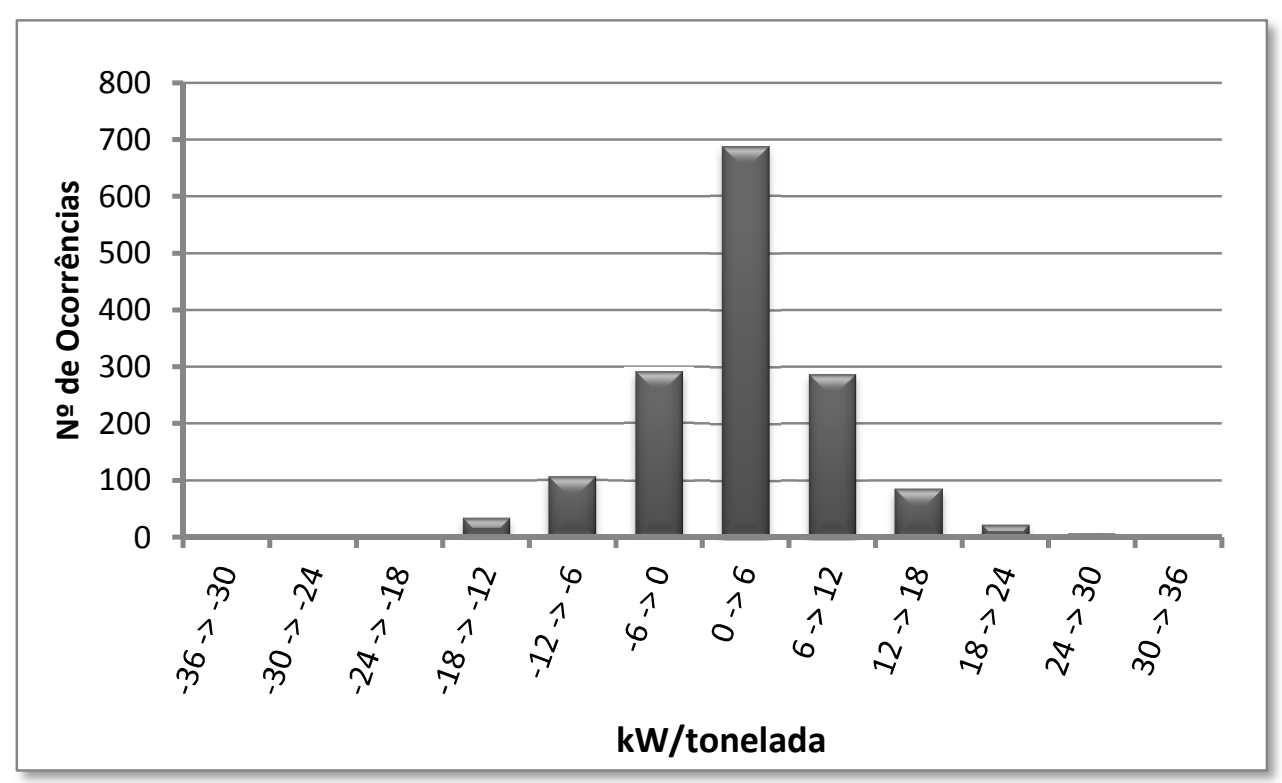

\section{DISCUSSÃO}

O levantamento de dados de trajeto por meio de aplicativos de celular tem menor precisão do que quando se utiliza um receptor de alta frequência, porém é um recurso de menor custo e que já se encontra a disposição de grande quantidade de pessoas. A pesquisa prévia 
apontou que tanto os modelos de aparelho celular como os aplicativos utilizados têm pouca influência na qualidade dos dados obtidos, desde que ambos estejam configurados adequadamente.

Os melhores resultados se deram com o celular operando em modo "normal", não sendo necessária a alta resolução, porém o aplicativo deve estar configurado para aquisitar os dados com a maior frequência disponível. $O$ consumo de bateria em um trajeto de uma hora se mostrou relativamente baixo. A filtragem dos dados conforme descrito acima se mostrou de simples execução e eficaz na redução dos ruídos sistêmicos do GPS, mas é preciso cuidado para que a atenuação não seja excessiva e distorça os valores.

O método de Pesquisa Colaborativa traz vantagens em relação a se utilizar um ou alguns veículos equipados com instrumentos de precisão. Primeiro, que por haver diversas pessoas efetuando medições simultaneamente, reduz-se o tempo necessário para se acumular um volume significativo de dados. Segundo, que para se determinar "comportamento típico" quanto ao VSP, a análise de uma grande quantidade de amostras, mesmo que com dados menos precisos, traz resultados melhores do que se estudar poucos dados de alta precisão, assim, a menor precisão do GPS de aparelhos celular é compensada pelo alargamento da base amostral, que permite cobrir mais e diversas situações de tráfego, clima e modo de condução.

As desvantagens em se adotar a Pesquisa Colaborativa são a possível falta de adesão, que limita o universo de dados e restringe o ritmo de trabalho, e quanto à qualidade dos dados em si, pois o protocolo de coleta e envio de dados deve ser previamente testado, claro, sem margem a interpretações dúbias, para se evitar a introdução de erros ou vícios na obtenção das informações.

\section{CONCLUSÃO}

O VSP é um fator que indica com precisão o quanto o veículo está sendo solicitado ao rodar nas ruas e estradas e traz relação direta com o consumo de combustível e as emissões de $\mathrm{CO}_{2}$ e de gases poluentes. O levantamento de valores típicos de VSP para determinada região ou trajeto permite avaliar se o condutor está operando o veículo adequadamente ou está super ou sub solicitando o mesmo.

A obtenção do VSP por meio de Pesquisa Colaborativa e com a utilização de aplicativos de celulares mostra-se um método interessante, que requer menos tempo para determinação de comportamento médio, por envolver um número maior de pessoas e circunstâncias avaliadas, desde que sejam seguidas as devidas precauções para a filtragem de ruídos ou inexatidões. 


\section{REFERÊNCIAS}

[1] PATHAK, S. K. et al. Real world vehicle emissions : Their correlation with driving parameters. Transportation Research Part D, v. 44, p. 157-176, 2016.

[2] IODICE, P. et al. Effect of ethanol-gasoline blends on $\mathrm{CO}$ and $\mathrm{HC}$ emissions in last generation SI engines within the cold-start transient: An experimental investigation. Applied Energy, v. 179, p. 182-190, 2016.

[3] LIU, Y.; CIRILLO, C. Evaluating policies to reduce greenhouse gas emissions from private transportation. Transportation Research Part D: Transport and Environment, v. 44, p. 219233, 2016.

[4] SILVA, C. M. et al. Evaluation of numerical models for simulation of real-world hotstabilized fuel consumption and emissions of gasoline light-duty vehicles. Transportation Research Part D, v. 11, p. 377-385, 2006.

[5] ZHANG, S. et al. Real-world fuel consumption and $\mathrm{CO} 2$ (carbon dioxide) emissions by driving conditions for light-duty passenger vehicles in China. Energy, v. 69, p. 247-257, 2014.

[6] PUJADAS, M.; DOMÍNGUEZ-SÁEZ, A.; DE LA FUENTE, J. Real-driving emissions of circulating Spanish car fleet in 2015 using RSD Technology. Science of the Total Environment, v. 576, p. 193-209, 2017.

[7] TSIAKMAKIS, S. et al. A simulation-based methodology for quantifying European passenger car fleet CO2 emissions. Applied Energy, v. 199, p. 447-465, 2017.

[8] JIMÉNEZ, J. L. Understanding and Quantifying Motor Vehicle Emissions with Vehicle Specific Power and TILDAS Remote-Sensing (Tese de Doutorado). Cambridge, Massachusetts: Massachusetts Institute of Technology, 1998, 361 p.

[9] ZHANG, K.; FREY, H. C. Road Grade Estimation for On-Road Vehicle Emissions Modeling Using Light Detection and Ranging Data. Proceedings, Annual Meeting of the Air \& Waste Management Association, June 20-23, p. 777-788, 2005.

[10] FONTARAS, G. et al. Development and review of Euro 5 passenger car emission factors based on experimental results over various driving cycles. Science of the Total Environment, v. 468-469, n. 2014, p. 1034-1042, 2014.

[11] WYATT, D. W.; LI, H.; TATE, J. E. The impact of road grade on carbon dioxide $\left(\mathrm{CO}_{2}\right)$ emission of a passenger vehicle in real-world driving. v. 32, p. 160-170, 2014.

[12] BOROUJENI, B. Y.; FREY, H. C. Road grade quantification based on global positioning system data obtained from real-world vehicle fuel use and emissions measurements. Atmospheric Environment, v. 85, p. 179-186, 2014.

[13] DUARTE, G. O.; GONÇALVES, G. A.; FARIAS, T. L. Analysis of fuel consumption and pollutant emissions of regulated and alternative driving cycles based on real-world 
measurements. Transportation Research Part D: Transport and Environment, v. 44, p. 4354, 2016.

[14] WANG, $\mathrm{H}$. et al. Modelling of the fuel consumption for passenger cars regarding driving characteristics. Transportation Research Part D, v. 13, n. 7, p. 479-482, 2008.

[15] ALMEIDA FILHO, F. G. V. PTR 5923 - Tecnologia de Rastreamento de Veículos apontamentos de aula - Ondas Eletromagnéticas. São Paulo: Universidade de São Paulo, 2017.

[16] RODRIGUES, M.; CUGNASCA, C. E.; QUEIROZ FILHO, A. P. de, Rastreamento de veículos. 1a edição. São Paulo: Oficina de Textos, 2009. 120 p. ISBN: 978-85-86238-87-1.

[17] COELHO, C. J.; PEDROSA, L.; VICENTE, S. C. Filtro média móvel. Anápolis: Anais do IX Seminário de PBIC - II Jornada de Ensino, Pesquisa e Extensão da UniEVANGÉLICA, Volume 1, 2011.

[18] COUTINHO, M. Introdução a filtros digitais - apontamentos de aula. Pelotas: Instituto Federal Sul-rio-grandense, Campus Pelotas, 2017. Disponível em:

<www2.pelotas.ifsul.edu.br/coutinho/Filtros_01.ppt>, acesso em 18/Nov./2017

[19] ABNT - Associação Brasileira de Normas Técnicas. NBR 6601 - Veículos rodoviários automotores leves - Determinação de hidrocarbonetos, monóxido de carbono, óxidos de nitrogênio, dióxido de carbono e material particulado no gás de escapamento. Norma técnica. ABNT: Rio de Janeiro, 2012. 54 p. 